EXEMPLARIA Classica

Journal of Classical Philology

22, 2018, 139-167

ISSN 1699-3225

\title{
UNA RECIENTE EDICIÓN DE LAS OBRAS MENORES DE TÁCITO
}

José Luis Moralejo, Tácito, Vida de Julio Agrícola. Del origen y situación de los germanos. Diálogo sobre los oradores. Prólogos, texto revisado, traducciones, notas e índices, Madrid: Consejo Superior de Investigaciones Científicas, 2017, ccclxii+173 pp. [dobles], ISBN 978-84-00-10219-7, e-ISBN 978-84-00-10220-3.

Casi 40 años después de habernos ofrecido la mejor traducción española de los Anales de Tácito (en adelante T.), el profesor José Luis Moralejo se ocupa ahora de las Obras menores del gran historiador, que ha editado, traducido, anotado copiosamente y largamente prologado para la colección "Alma Mater" del CSIC.

Tras el breve "Prefacio" de rigor en el que Moralejo (en adelante M.) ya entra en materia al subrayar el "carácter de únicas" de cada una de esas obras -biografía histórica en el caso del Agricola, monografía etnográfica en el de la Germania y "unicidad", en cuanto a lo singular de su asunto y de su estilo, del Diálogo sobres los oradores-, se disponen sucesivamente las tres obras precedidas cada una de su prólogo: Agricola (xvii-cxi + 1-48, estas dobles), Germania (cxiii-ccxx + 49-99, estas dobles) y Diálogo (ccxxiii-ccclxvii + 101-159, estas dobles). Las obras se presentan en el orden tradicional por más que M. declara aceptar la tesis de Murgia que considera el Diálogo como la primera escrita de las tres (xviii). El volumen se enriquece también con dos mapas, uno de Britania (xvi) y otro de Germania (cxiv), y se corona con un Index nominum de las tres obras (161-173).

En primer lugar, examinaremos los tres extensos prólogos, después haremos algunas observaciones sobre el texto y el aparato crítico, y por último, comentaremos brevemente algunos aspectos de la traducción y las amplias notas que la acompañan ${ }^{1}$.

${ }^{1}$ José Luis Vidal se ha encargado fundamentalmente de la revisión de los prólogos, traducciones y comentarios. A cargo de Pere Fàbregas han corrido los comentarios sobre la transmisión textual y la crítica del texto. Naturalmente, ambos autores son solidariamente responsables del conjunto de la recensión. Los autores quieren dar testimonio de su agradecimiento a la Fondation Hardt (Vandoeuvres, Ginebra), en cuya sede se gestaron parte de estas páginas. Por otra parte, el trabajo se inscribe en el proyecto de investigación FFI-201341056-P del Ministerio de Ciencia, Innovación y Universidades (España). 


\section{LOS PRÓLOGOS}

\section{Agrícola}

En su introducción a la Vida de Julio Agrícola (Agr. en adelante) M. destaca, al ocuparse de la cronología de la obra, la tesis "innovadora" de Tscherniak según la cual Agr. nace como parte de una historia de la época flavia que T. no llegó a escribir (xviii). Se ocupa a continuación de la figura de Julio Agrícola, cuya biografía traza brevemente siguiendo sobre todo las fuentes proporcionadas por Syme (xix-xxii). T. entra en la vida de Agrícola cuando formaliza su matrimonio con la hija de este, lo que explica el breve tratamiento conjunto (xxii-xxv) que M. dedica a esas dos figuras, a su medio y a su época.

Al ocuparse a continuación del género literario y el objetivo del Agr. (xxv-xxxvi), M. vuelve sobre su a nuestro juicio acertada opinión de que el carácter de unicum de la obra se explica porque se sitúa en "la encrucijada de varios géneros", la historiografía, la biografía y el "estrato más viejo y autóctono de la oratoria romana, el de las laudationes fúnebres" (xxvi). Repasa a continuación el autor el "vaniloquio filologico" (Marchesi) que se ha producido sobre ese tema del género literario del Agr. y se inclina por aceptar la opinión de Petersmann, quien prefiere hablar de la "forma literaria" más que del "género literario" de la obra, opinión que M. enriquece con la consideración de consolatio que tiene su epílogo. El problema del encuadramiento genérico del Agr., advierte M., viene imbricado con el de las intenciones de T. al escribirlo. Salta a la vista su carácter apologético, no solo de la conducta de Agrícola, sino de la propia de T. durante la tiranía de Domiciano, que vienen justificadas - no sin un punto de vergüenza propiafrente a las inútiles actitudes de los "mártires" que considera indebidamente apreciados. M. reseña, entre las copiosas opiniones de los estudiosos, las que advierten en la obra otros objetivos: desenmascarar la propaganda del falso éxito de Domiciano sobre la Germania contrastándola con la realidad de la obra realizada por Agrícola en Britania, y, al mismo tiempo, elaborar un manifiesto del imperialismo romano que justifique la dominación de Britania. Da cuenta el autor a continuación de las opiniones que señalan también como intención de $\mathrm{T}$. el dar rienda suelta al rencor y los resentimientos del propio T. y de su suegro que convergen en la figura de Domiciano, así como de otras "variantes hipercríticas de la exégesis del Agricola" que M. denomina - con aguda y erudita utilización de palabras de Karl Popper- "hipótesis "no falsables" (xxxvi).

En el apartado dedicado las fuentes literarias, lengua y estilo del Agr. (xxxvi-li), después de hacer justicia de los importantísimos trabajos de Wölflin, que abrieron nuevas vías - "bahnbrechende" como gusta decir M. aquí y en otros casos, rindiendo tributo a lo sólidamente germánico de su formaciónen la investigación de estos temas, M. señala la confluencia de una doble tradición, la retórica y oratoria que Cicerón representa de manera señera, y 
la historiográfica de Salustio. Pasa revista a continuación a la deuda del Agr. con la prosa oratoria y retórica del Arpinate, citando numerosos ejemplos y recogiendo las opiniones de los que ven también una influencia, aunque menor, del uso ciceroniano en la sujeción, ciertamente discreta, a las cláusulas métricas, aspecto que sería desechado posteriormente en la obra mayor del autor. De la deuda con Salustio se señalan el uso del infinitivo histórico, la inserción de digresiones para separar los episodios narrativos (rasgo este que también puede deberse a la influencia de Livio), el uso de sententiae y el carácter de algunos discursos. En menor grado se ejerce la influencia de Livio, aunque es más notable en el Agr. que en las obras mayores. Ahora bien, subraya M. que otros rasgos de estilo no pueden ponerse a cuenta de la influencia de aquellos y otros autores que cita. Son los propiamente tacíteos que en esta obra menor ya se pueden rastrear y que luego pasarían a ser propios del estilo de T. Recoge entre ellos, la preferencia de la uariatio sobre la concinnitas, rasgo del que da abundantes ejemplos (xlvii) con escrupulosa cita, en su caso, de los estudiosos que los han detectado -es este, el cuidado en mencionar las fuentes secundarias, un proceder constante en M., un ejemplo, entre otros muchos, de la honestidad científica que lo caracteriza-; añade el influjo del carácter epigramático de la prosa de Salustio, lo que da lugar a las famosas sententiae que rematan los periodos de T., algunas de las cuales siguen utilizándose en nuestros días; finalmente señala la breuitas como la característica general de la prosa tacítea. Es precisamente estudiando en el Agr. esos rasgos de lo que, remedando a Fraenkel, podríamos llamar "tacíteo en Tácito" como Murgia descubre, señala M., que "los vestigios de las fuentes aludidas parecen haber llegado precisamente por vía del Diálogo [sobre los oradores]", lo que le lleva a considerar el Diálogo como primera obra de T., opinión que convence a M. quien además señala que la consiguiente datación de esa obra en el 97 permite respetar la tradicionalmente admitida para el Agr. del 97/98 (xlviii-xlix). Finalmente M. hace una "referencia singular" al parecer de Forni, quien rechaza la communis opinio sobre las fuentes literarias del Agr. y señala que se trata más bien de lugares comunes. Finaliza este apartado M. con la cita de dos representativos ejemplos de estilo elegidos por Woodman, uno del estilo periódico de ascendencia ciceroniana (Agr. 35.4) y otro de carácter típicamente salustiano (20.2), "en suma", concluye acertadamente M., "dos estilos, los de Cicerón y Salustio, el segundo de los cuales se impondría en la prosa madura del historiador".

En el apartado dedicado a las fuentes documentales del Agr., M. establece una primera división entre aquellas que $\mathrm{T}$. pudo recabar directamente de su suegro, Agrícola, y del medio familiar y próximo al biografiado y las fuentes escritas, "históricas, geográficas y etnográficas" especialmente las referidas a Britania (liii-lvi). Entre ellas cabe señalar en primer lugar -aunque T. no lo reconozca expressis uerbis- a César; en seguida las dos fuentes que sí cita, una parte para nosotros perdida de Livio y el también perdido historiador Fabio 
Rústico. Noticias geográficas y etnográficas pueden proceder posiblemente de autores griegos como Estrabón, Píteas de Marsella y de latinos, señaladamente Plinio el Viejo y Pomponio Mela.

El apartado dedicado a la tradición ms. del Agr. (lvi-lxiv) está fundamentalmente centrado, como es lógico, en la larga y complicada discusión sobre si el cuaternión en letra carolingia (ff. 56-63 = Agr. 13.1 munia - 40.2 missum) del codex Aesinas (que, aunque resulta prácticamente ilegible, se conserva en Roma, Biblioteca Nazionale, Vitt. Emm. 1631) puede o no identificarse con los restos del perdido códice Hersfeldensis, del que derivan, de una forma u otra, los otros tres manuscritos del Agr. (A, B y T, s. XV) y también los suplementos del s. XV del Agr. en el Aesinas (ff. 52-5 y 64-5). Aunque M. no deja de señalar los argumentos en contra de tal identificación, se inclina finalmente por aceptarla como hacen, con buenas razones, la mayoría de estudiosos. M. designa, siguiendo a Ogilvie ${ }^{2}$, la parte carolingia del Aesinas con la sigla $\mathrm{E}$ y la parte humanística con e (cf. lxxxv). Se echa en falta algún comentario adicional sobre el valor de las lecturas de $\mathbf{E}^{2}$, contemporáneo de $\mathbf{E}^{1}$. En opinión de Delz ${ }^{3}$, dichas lecturas debían de proceder de otro códice, lo que parece razonable, teniendo en cuenta que $\mathrm{E}^{2}$ mezcla errores evidentes (e.g. 16.2 dubius; 25.1 uinum) y lecturas buenas (e.g. 18.1 aestate; 19.4 exactionem; 20.1 incuria). Precisamente, las variantes alternativas presentes en el Hersfeldensis facilitaron la contaminación en la transmisión humanística del Agr., lo que hace casi imposible determinar de forma clara e incontrovertible la filiación de esos códices.

El más largo de los apartados del prólogo al Agr. es el dedicado a la pervivencia de la obra (lxiv-lxxx) y en él da pruebas M. de su amplio conocimiento de la historia de las literaturas europeas y de las ideas, de su dominio de la bibliografía y de su vasta cultura. Abre M. este apartado con la referencia obligada al tacitismo, cuyos primordios en los quinientistas florentinos, Maquiavelo y Guicciardini, señala. Ciertamente el Agr. con dificultad se podría considerar como una fuente de esa tradición, "dada su condición de opus minus", pero M. nos sorprende con una muestra curiosísima de los vericuetos por los que puede discurrir la tradición clásica: las Grampian Mountains, en Escocia, deben su denominación a un error de lectura montem Grampium del correcto montem Graupium de los mss. en Agr. 29.2 y el error, además, viajó "hasta los antípodas para dar nombre a las Grampian Mountains de Australia".

Después de tan jugoso aperitivo el lector puede acopiar fuerzas para seguir el curso de la pervivencia del Agr. (lxiv-lxxx), viaje para el que M. sigue la

${ }^{2}$ M. Winterbottom, R. M. Ogilvie (edd.), Cornelii Taciti opera minora recogneverunt brevique adnotatione instruxerunt, Oxonii 1975 [Agr. rec. Ogilvie, Germ. et Dial. rec. Winterbottom].

${ }^{3}$ I. Delz (ed.), Corneli Taciti libri qui supersunt, Tom. II, Fasc. 3, Agricola, Stutgardiae 1983, iv. 
guía de López-Cañete, sin renunciar, claro está a sus propias aportaciones. Después de un rápido recorrido por la incierta presencia de la obra de T. en la Antigüedad y en la Edad Media, es a partir del Renacimiento cuando, codice Hersfeldensi mediante, comienza la verdadera fortuna del Agr. Humanistas empeñados en escribir historias nacionales en Inglaterra y Escocia lo utilizan de forma especial, tanto que más tarde se convertiría "en referencia obligada del nacionalismo escocés” y, por este camino, llegaría hasta percibirse en el Acta de Unión de 1707 “cuya revocación, por cierto”, añade M. en una de esas pinceladas eruditas, curiosas y a veces finamente irónicas, "se ha replanteado recientemente". Una forma particular de recepción del Agr. especialmente en el ámbito anglosajón subraya la oposición entre el imperium (naturalmente el romano) y la libertas (aquella por la que lucharon los britanos dominados por Roma). No es de extrañar que entonces el Agr. fuera reivindicado tanto por los defensores del imperialismo (por supuesto, británico) como por sus críticos. Sigue M. con un nutrido repaso a la pervivencia del Agr. en el ámbito anglosajón durante los siglos XVII al XIX y aquí de nuevo nos sorprende con una interesante y en muchos aspectos curiosa noticia de esa pervivencia en las épocas victoriana y eduardiana, con estupendas referencias a Disraeli, Gladstone, Lord Kitchener, N. Chamberlain y, al final, de la mano de su yerno, el nefasto teórico racista Houston Stewart Chamberlain, al mismísimo R. Wagner, un final de la excursión que nos parece especialmente oportuno a los que firmamos esta nota.

Sin embargo, se echan de menos aquí noticias de la pervivencia del Agr. en los autores del Continente -con excepción, claro está, de España, de la que pasa a ocuparse a continuación (lxxviii-lxxix). No sabemos si esta laguna tiene su razón de ser en la escasez de los datos o en la necesaria selección de los mismos que el autor ha considerado prudente imponerse. Sí es considerable el espacio dedicado, también esta vez en parte de la mano de López-Cañete, a la recepción española del $A g r$. que en algunos momentos se trata vinculada a la recepción general de la obra de T. Para acabar ese apartado de la pervivencia vuelve M. a la recepción anglosajona del Agr. y, concretamente, a la opinión de Trilling que evoca "la única frase de él que todo el mundo conoce", la del jefe britano Calgato contra el imperialismo romano: ...ubi solitudinem faciunt pacem appellant (Agr. 30.5), la "pace del sepolcro" -nos permitimos añadir nosotros confiando en la benevolencia de M.-, aquella que el Marqués de Posa espeta a Felipe II en el Verdi que traduce a Schiller.

En el apartado dedicado a las ediciones y traducciones del Agr. (lvilxiv), M. empieza señalando justamente que el descubrimiento del Aesinas a principios del s. XX marcó un claro punto y aparte en el esclarecimiento crítico de la obra. M. elude aquí ofrecer un repaso detallado de la historia editorial del Agr. y se limita a glosar las traducciones y ediciones producidas en el ámbito hispánico. M. suscribe la opinión de Sanmartí según la cual en España no ha existido una tradición de comentarios y ediciones que tuvieran 
como objetivo el establecimiento del texto, y resalta (lxxxiii) la novedad que en ese sentido ha representado la edición de López-Cañete (2013).

Por último (lxxxiv-lxxxv), M. indica que su edición presenta un "texto revisado" que toma como primer punto de partida el de Koestermann (1970), pero que ha tenido también en cuenta las ediciones de Saint-Denis (1942 [no 1042]), Lenchantin de Gubernatis (1949), Till (1961), Ogilvie-Richmond (1967), Ogilvie (1975), Delz (1983; 2010²), Forni (1962), Soverini (2004), López-Cañete (2013) y Woodman (2014). De estas ediciones proceden fundamentalmente las lecturas de A, B y T (citados de forma muy restringida, puesto que son irrelevantes para el establecimiento del texto cuando se dispone de $\mathrm{E}$ ), pero también de las ediciones antiguas. Por otra parte, M. sí realizó una colación personal del Aesinas a partir de la reproducción publicada por Till $(1943)^{4}$, lo que sin duda es de agradecer (se puede comprobar, por ejemplo, en su aparato crítico en Agr. 15.3, donde M., p. 18, anota "delectus E, ubi perperam dilectus edd. legunt", contradiciendo el testimonio, por ejemplo, de Delz $z^{5}$; en el códice, f. 56 , la primera vocal no está muy bien definida, pero parece que se trata, efectivamente, de una $e)^{6}$. Asimismo, M. señala que en su aparato ha restringido la cita de contribuciones modernas a los pasajes que Ogilvie, Saddington, Wellesley, Murgia y Martin señalaron como loci disputati.

\section{Germania}

Pasamos ahora a considerar el estudio que M. dedica a uno de "los cien libros más peligrosos que jamás se hayan escrito" (Momigliano), si no es que se trata de El libro más peligroso, como quiere Krebs, que así titula su libro dedicado a la Germania (en adelante Germ.) de T.

Por lo que hace a la fecha de composición de la obra aduce M. los datos que arropan la datación tradicional, en el 98 o muy poco después, pero da cuenta también de la hipótesis (Schuhmann) que da como terminus post quem los años 103-106. Por su parte Tscherniak sostiene que la Germ. comenzó a elaborarse en la época de Domiciano, y también como un trabajo preliminar, al igual que habíamos visto en el caso del Agr., para la composición de una historia de Roma bajo los Flavios.

Dedica M. un importante apartado (cxviii-cxxiii) al examen de la posición de la Germ. en la tradición etnográfica antigua y puntualiza que, efectivamente, cabe hablar más de una tradición que de un género o, en todo

${ }^{4}$ Unas fotografías antiguas del códice pueden ahora consultarse en http://id.lib.harvard. edu/alma/990072856120203941/catalog [19/08/2018]. La reproducción viene precedida de una interesante nota sobre las vicisitudes del ms. durante y después de la Segunda Guerra Mundial.

${ }^{5}$ Delz, Agricola, 12.

${ }^{6}$ M. también indica que ha tenido a la vista el manuscrito también para la Germ., pero reconociendo que para esa obra se trata solo de "uno más de los códices a considerar" (cxci). 
caso, de una variedad literaria que primeramente se presentó como excursus de "obras históricas, geográficas, paradoxográficas o enciclopedias y solo en ocasiones parece haber alcanzado el formato de monografía externa". Fueron Trüdiger, primero, y Norden poco después quienes decididamente colocaron la obra en la ya larga cadena literaria de la etnografía que empezó en los creadores jonios de la prosa griega. Así pues, señala M., T. tenía a sus espaldas varios siglos de tradición etnográfica griega y latina, a la que pasa breve revista (cxx-cxiii). Mommsen, sin negarle ese carácter etnográfico, la consideró como, otra vez, un "trabajo preliminar" ("Vorarbeit") para la redacción de las Historiae y Paratore abundó en esa opinión.

A la estructura y contenido de la Germ. dedica M. el siguiente apartado de su Prólogo (cxxiii-cxxviii) en el que se basa fundamentalmente en la importante edición y comentarios de Gudeman. M. resigue la bibliografía posterior, se detiene en los puntos más debatidos, que analiza con su acostumbrado buen criterio, y destaca cómo T. renuncia a tratar lo que designa como cetera iam fabulosa (46.4) no solo porque ya ha llegado en su descripción al último confín de la Germania, sino porque se trataría de mirabilia, hechos y cosas fantásticos que no está en su intención abordar.

Es verdad que decir, como hace Lund en su investigación de las fuentes de la Germ., que estas se remontan en última instancia a "informantes nativos" parece ser lo que M., al comenzar el apartado dedicado a esa cuestión (cxxixcxxxiii), llama castizamente una perogrullada. Lo que hay que determinar es cuáles son las fuentes intermedias y cuál su fiabilidad. Gudeman las divide en fuentes primarias, que serían las noticias recabadas por T. en Germania y fuentes secundarias, las facilitadas por textos literarios o por informes de viajeros y no cree en la existencia de las primarias. Norden concede alguna mayor importancia al material transmitido oralmente y a lo que él llama informaciones "medio literarias", básicamente relatos de comerciantes y viajeros familiarizados con Germania. A continuación, M. da cuenta de la opinión mayoritaria, a saber, que T. trabajó sobre todo con fuentes literarias, y resume lo que podríamos llamar doctrina común al respecto, destacando que, si bien es César la única fuente expresamente citada, probablemente es de Plinio el Viejo, concretamente de su obra perdida De bellis Germaniae y, en menor medida, de su Naturalis Historia, de donde en mayor medida depende T. Finalmente cita M. la opinión de Syme, quien sobre la posibilidad de que T. trabaje sobre buena información cercana a las fuentes primarias expone su "strongly negative veredict". M. cierra con hábil y modesta recusatio ("Syme dixit, y nosotros no nos sentimos con fuerzas para discutir su parecer") este aparatado dedicado a la uexata quaestio de la Quellenforschung.

Más debatida todavía es la siguiente cuestión que se estudia (cxxxiiicxxxviii), la de las intenciones (relevante cursiva del autor) u objetivos de la Germ. Antes de entrar en materia, M. expone muy acertadamente unas precisiones de carácter metodológico entre las que destaca su opinión de que este 
tipo de cuestiones, al tratarse más bien de un juicio de segundas intenciones, es decir de las latentes pero no expresadas por el autor, "plantean al estudioso un desafío más atrayente”. Expone a continuación el estado de la cuestión a partir de la opinión de Borzsák quien establece que a T. le interesaba desenmascarar la propaganda oficial de Domiciano sobre el supuesto sometimiento de la Germania, propaganda que intentaba cubrir el fracaso de la expedición del emperador al confrontarla con la realidad de la Britania dominada por Agrícola. Otros autores (Timpe, Lund) subrayan el objetivo, eminentemente político, del libro: describir la Germanorum libertas (37.3) como opuesta a la situación política de Roma bajo el Imperio. Intencionalidad política descubren también Nesselhauf y Rives, estableciendo este último que no hay razón para buscar una única motivación de la Germ., sino un complejo de ellas. Con buen criterio, en fin, propone M. una opción “más llana y sencilla [...] que entonces, como ahora, la literatura sobre pueblos y extraños y lejanos tuviera un público curioso propio, a cuyas demandas trataran de responder T. y otros autores con obras como la Germania" (cxxxviii).

La cuestión de hasta qué punto podemos considerar la Germ. como fuente histórica y cuál es su fiabilidad es la que el autor desarrolla en las siguientes páginas de su obra (cxxxix-cli). M. pasa revista a opiniones de los estudiosos (Norden, Lund, Rives) que advierten que en la descripción de la Germ. y de sus habitantes T. se conforma con los planteamientos de la etnografía antigua, utilizando una serie de "estereotipos" (Rives) -los "Wandermotive" de Norden-, cuando no atribuyendo a los germanos virtudes propias de los antiguos romanos. Cerca de eso está la llamada interpretatio Romana, por medio de la cual T. "establece analogías o contrastes explícitos" entre instituciones, ritos, dioses romanos y germanos. Cuando esa relación se establece en el terreno moral y se adentra en el tópico de la comparación entre la pureza de la sociedad primitiva y la corrupción de la sociedad urbana y desarrollada estamos, advierte M., ante el "mito rousseauniano" de la idealización del salvaje. Son estos hechos los que imponen cautela a la hora de tratar de la fiabilidad de la Germ. Pero cuestionarse esa fiabilidad es algo que inquieta a las posiciones "ortodoxas", léase "alemanas" que, sobre todo a partir de los años veinte del siglo pasado, consideran la Germ. como un "documento histórico indubitable". Es el caso de la interpretación pangermanista de Peterka y de trabajos (Bickel, Naumann) que cada vez se acercan más peligrosamente a las tesis racistas y a conceptos y expresiones que preparan el camino de la funesta recepción alemana de la Germ. en el nacionalsocialismo. No extrañará que después de la guerra se volviera a una actitud crítica en cuanto a la utilización de la Germ. como fuente histórica, devaluándola como tal y considerándola sobre todo como literatura. M. pone de relieve lo que tiene de oscilación pendular esa reacción y da cuenta de las posiciones conciliadoras de Rives y Krebs. 
Como punto de partida para su tratamiento del tema de la lengua y el estilo de la Germ. (cli-clviii), M. recoge la opinión establecida de que, mientras que en el Agr. tiende hacia el estilo de Séneca, en la Germ. T. se vuelve hacia Salustio (Perret, Syme). Pero M. advierte de que ya en la Germ. "se aprecian [...] la expresión característica y los recursos que hacen inconfundible la prosa de T. historiador" (cli-clii), de suerte que la evolución de su estilo más bien procede de la diferente dosificación de esos recursos. Es de nuevo el estudio de Gudeman sobre el estilo y recursos retóricos de la Germ. el más sistemático y completo, a pesar de su brevedad, y el que mantiene toda su validez, así que M. lo sigue en las páginas que siguen (cliv-clvii). Finalmente el autor enriquece ese tratamiento exponiendo una serie de ejemplos muy bien elegidos de típicas sententiae -esas con las que T. corona algunos capítulos del libro y que son tan características de su estilo (clvii-clviii).

A continuación (clviii-clxxv), M. pasa a tratar la tradición manuscrita de Germ., más compleja que la del Agr. La Germ. se conserva en unos 30 códices del s. XV que, en último término, se remontan al Hersfeldensis, pero con fuertes discrepancias entre los editores sobre el valor y genealogía de los mismos, lo que, naturalmente, ha condicionado profundamente la historia editorial del texto (y, por esa misma razón, $\mathrm{M}$. ha decidido abordar los dos aspectos de forma más o menos conjunta). Al tratarse de un texto revisado, para el que no ha realizado una recensio personal de los mss., M. procede a recoger las distintas posiciones que han existido y admite, de entrada, que hay 9 mss. que se consideran fundamentales "a la hora de establecer el texto del arquetipo" (clx) y que coinciden, por cierto, con los 9 que Önnerfors ${ }^{7}$ empleó preferentemente en su edición y, en buena medida, con los 7 mss. principales de Winterbottom ${ }^{8}$. Finalmente, después de resumir las diversas valoraciones que se han hecho de los distintos mss., M. acaba por compartir la opinión de Perl de que, a fin de cuentas, la teoría estemática resulta poco útil para el establecimiento del texto (clxxii), lo que no es de extrañar si, como parece, los mss. de la Germ. sufrieron cierto grado de contaminación y, como advirtió Murgia y M. recuerda, el Hersfeldensis contenía ya variantes alternativas (como hemos visto más arriba a propósito del $\mathrm{Agr}$.).

Por ello, acertadamente y siguiendo la recomendación de Murgia, M. rechaza (cxci) el sistema de cita de los mss. por "familias" a la manera de Winterbottom y prefiere citar los códices separatim como Önnerfors. No hay, de todos modos, un reconocimiento explícito sobre a qué editores debe más el texto de la Germ. que presenta M.

Luego (clxxv-clxxvi), M. dedica aproximadamente el espacio de una página a recordar algunos los comentarios más importantes de la Germ.,

${ }^{7}$ A. Önnerfors (ed.), Corneli Taciti libri qui supersunt, Tom. II, Fasc. 2, De origine et situ Germanorum liber, Stutgardiae 1983.

${ }^{8}$ Winterbottom, Ogilvie, Opera minora. 
empezando por el monumental de Müllenhoff, para pasar rápidamente a mencionar las traducciones de la Germ., con especial énfasis en las hispánicas (clxxvi-clxxviii).

Largo y enjundioso es el apartado dedicado a la Germ. en la posteridad (clxxviii-cxc). La fortuna de esta monografía es especialmente rica y compleja, cuando no dramática, en Alemania, como sería de esperar. En época humanística es Conrado Celtis quien basa en la Germ. la lección inaugural de 1492 en la Universidad de Ingolstadt donde defiende la primacía del emperador sobre el papa. Ya antes, en 1458, Eneas Silvio Piccolomini (más tarde Pío II) saca "la Germania a la palestra cultural e ideológica con su De ritu, sito, moribus et condiciones Germanorum" (1458) donde se alaba la acción de la romanidad civilizadora, léase de la Iglesia Romana, sobre los pueblos bárbaros. En cambio, en Alemania se desarrolla una utilización política de la Germ. con motivos recurrentes y de muy diversa índole: por ejemplo, para defender la germanidad de Alsacia; o alimentando "la hoguera de la rebelión antirromana que atizaba Lutero" (clxxxii). El siglo europeo por excelencia del tacitismo, el s. XVII, vuelve su atención sobre todo a las obras mayores de T., pero M. ha espigado entre las fuentes y la literatura secundaria algunas muestras de la pervivencia de la Germ. al lado de aquella corriente más impetuosa. No fue la Ilustración una época especialmente receptiva para la Germ., aunque en Francia Montesquieu y en Alemania Herder la conozcan bien. En cambio, el Romanticismo alemán, de signo profundamente nacionalista y con su irredenta búsqueda de la unidad "en la Alemania fragmentada en pequeños estados, y más desde que su casi milenario Reich había sido degradado por el aventurero corso a la subalterna condición de Imperio Austríaco" (clxxxiv, estupenda la expresión de M. quien no sin optimismo da por descontado que nadie dudará de quién sea el "aventurero corso") abrió un camino para la recepción de la Germ. que iba a tener consecuencias nefastas. Al llegar aquí M. abre una casi écfrasis sobre el tratamiento de la Germ. por los intelectuales y propagandistas del nacionalsocialismo, deteniéndose un tanto en ejemplos conspicuos como el de Rosenberg (clxxxv-cxc, con un error en la numeración de las páginas: la que sería clxxxviii viene como clxxxiii). Lo hace con la erudición a que nos tiene acostumbrados y con una prosa enérgica que llega al patetismo cuando nos recuerda, por ejemplo, y refiriéndose al citado Rosenberg "que en Núremberg subiría los trece peldaños del cadalso sin haber cedido un ápice en el odio implacable a los hijos de Israel”. Estos rasgos de estilo de M. brillan, prudentemente dispensados, entre su sólida prosa científica y constituyen, a nuestro juicio, repères muy de agradecer. El final de este apartado dedicado a la fortuna de la Germ. incide ya en la cuestión de su tradición manuscrita, puesto que M. lo dedica a la "rocambolesca" anécdota que tuvo como inerte protagonista al códice Aesinas. Es una historia que tiene sus visos de thriller, por lo que sería impropio resumirla aquí, y que, por otra parte, M., suponemos que con media sonrisa, no descarta ver algún día en las salas de cine. 


\section{Diálogo sobre los oradores}

Al abordar el estudio dedicado al Diálogo sobre los oradores (en adelante Dial.) M. distingue, naturalmente, en el apartado dedicado al título y a la fecha de la obra (ccxxv-ccxxxviii), la data en la que se desarrolla su acción ficticia de la data real en que T. la escribió. La primera hay cierto consenso en situarla hacia los años 77/78. Las novedades vienen en cuanto se intenta datar la escritura de la obra. Frente a la fecha tradicionalmente aceptada, en torno al 102, y la consideración del Dial. como la última de las tres obras menores de T., Murgia la considera la primera de ellas y propone el año 97, un poco antes de la publicación del Agr. Un detenido estudio de los loci similes con Quintiliano y de las expresiones del Dial. que recurren en Plinio el Joven, lo lleva a proponer, respectivamente, un término post quem tras la publicación de la Institutio oratoria de aquel (ca.95/96), y el término ante quem lo deduce del conocimiento que Plinio muestra del Dial., ya en el primer libro de sus epístolas, que vio la luz en los años 97/98. Brink somete el trabajo de Murgia a una estrecha crítica, para acabar proponiendo una fecha que reconoce "incómodamente amplia", entre los años 98 y 103.

Aunque tiene consecuencias que afectan a la datación de la obra, la cuestión más importante y polémica que ha suscitado la obra -y que, por lo demás, se imbrica con la de su datación- ha sido la de la autoría del Dial. (ccxxxviiii-ccliii), pues esta obra es la única de las atribuidas a T. que plantea problemas de autenticidad. M. discierne cuidadosamente dos cuestiones en torno a esa principal: "la previa de en qué condiciones de atribución llegó la obra a la época moderna y la sustancial de si realmente se trata de una obra de Tácito" (ccxxxix). Para solventar la primera debería ser capital el testimonio de los códices y, al respecto, Robinson dejó claro que la tradición manuscrita avalaba la autoría, opinión que Häussler reforzaría estudiando los testimonios de los humanistas del siglo XV. Ahora bien, si esa atribución es acorde con la realidad, si el Dial. es o no de T., al margen de que se lo atribuya la tradición manuscrita, ésa es la uexata quaestio. Propone M. abrir el tema teniendo en cuenta una prudente observación de Mayer: el autor del Dial. no intenta pasar por T., no se trata de un falsario, no estamos ante un fake, como dice M. Gudeman había abordado el estilo de la obra en relación con la cuestión de su autenticidad y estableció con toda rotundidad que el argumento estilístico de ninguna manera servía contra la atribución a T. de la obra. Por otra parte, el estilo de un autor antiguo está "condicionado por la elección del género literario en que en cada ocasión se inscriba” (ccxlvi), de ahí que por ese camino no es probable encontrar argumentos contra la autoría. Recoge a continuación M. el llamado “argumento de Lange”. Reparó este autor en que Plinio el Joven recoge en un pasaje de sus cartas (9.9.2), concretamente en una dirigida a T., unas expresiones empleadas por este en el Dial. (9.6 y 12.1), de lo que sacó consecuencias en cuanto a la cronología y atribución positiva de la obra a T. Desde luego frente a estas posiciones 
no son menores ni poco autorizadas las que sostienen lo contrario, que el Dial. no es de T. Es la opinión de Paratore mientras que Syme -y con ello quedan citados dos gigantes de la investigación sobre T. en el s. XX- no ve razones para negar la autoría de T. Murgia, con cuya datación del Dial. M. se muestra conforme, como acabamos de ver, mantiene la autoría de T. en conclusiones derivadas de aquellas sobre la fecha de la monografía. Al lado de tantos y tales nombres es muy satisfactorio comprobar la importancia que da M. a los trabajos del Prof. Ballester, colega nuestro de la Universidad de Valencia, que niega tenazmente la paternidad tacítea del Dial. M. repasa detenidamente los argumentos de Ballester y observa que, con independencia de que convenzan o no $-\mathrm{y}$ M. tras ponderarlos no los ve suficientes ni de tal índole como para negar la atribución-, "la aportación de Ballester contiene una parte positiva y constructiva" (ccli) y arroja nueva luz sobre la proximidad, indudable, del Dial. con Quintiliano, a cuyo círculo atribuye Ballester la paternidad de la obra después de dar argumentos de comparación lingüística, ideológicos y literarios, prosopográficos y estilísticos -todos ellos atentamente considerados por M. Son sobre todo estos últimos los que no le parecen convincentes: Ballester, entiende M., parece aplicar a estos autores antiguos la "concepción buffoniana del estilo". Y, frente al famoso aserto de le style c'est de l'homme même, afirma con razón que en la Antigüedad clásica más bien le style c'est du genre même y de ahí la cautela con que se deben tomar los argumentos estilísticos para apoyar conclusiones referidas a cada autor en particular.

M., en el apartado dedicado a la prosopografía del Dial. (cclxiii-cclxxv), observa que los protagonistas de la "tertulia" (castiza palabra que el autor usa a despecho del mal uso que de ella se hace -de la cosa designada- en los media) parecen proceder de los que Syme llama "rising Provincials". De los dos primeros en aparecer en escena, Marco Apro y Julio Secundo, Apro era originario de la Galia y forma parte de lo que con feliz denominación el propio M. llama "círculo de la Narbonense", al que adscribe a Agrícola y al propio T. Secundo, por su parte, procede también de la Galia, pero no de la Narbonense. Su participación en la conversación es muy poca, desempeñando más bien el papel de espectador o de árbitro del debate. Es Curiacio Materno quien ha planteado mayores problemas prosopográficos, en primer lugar el de si debe ser identificado con otro Materno, un declamador ejecutado por Domiciano en el año 91, a lo que la crítica en su mayor parte da una respuesta positiva. Pero ahora "entran en escena", escribe M. otros dos candidatos. Señalemos primero para el lector no advertido que no es que entren en la escena del diálogo $-y$ en el contexto del que se está hablando todo apunta al riesgo de interpretarlo así-, sino en la "escena" de la discusión filológica. Efectivamente, los estudiosos han propuesto también el nombre de $M$. Cornelius Nigrinus Curiatius Maternus y quizá también el del Curiacio y/o Materno citado en Marcial (6.60.3). En fin, afirma M. tras pertinente discusión, no hay razón 
para pensar que todos esos Maternos compartan identidad. Avanzado el debate llega a escena, esta vez sí, la del diálogo, Vipstano Mesala, pariente del famoso M. Valerio Mesala Corvino. M. propone, para finalizar este apartado, un ensayo de caracterización de los personajes, especialmente convincente en el caso de Materno, la descripción de cuyo carácter le lleva hasta una sabrosa alusión a Ortega y Gasset, que no sabemos si resulta "inevitable" (cclxxiv, n. 127), pero sí se lee con gusto.

¿Cuál es el tema o los temas del Dial.?, esto es lo que se plantea M. en el título del siguiente apartado (cclxxv-cclxxxi). Ya que M. acaba de aludir a Ortega, orteguiana parece ser su propuesta de considerar el Dial. como un "documento de historia de las mentalidades". Hay un terma general que podría considerarse en la estela de la obra perdida de Quintiliano De causis corruptae eloquentiae. Es posible, como señala con acierto M., que ese tema tarde un poco en imponerse "eclipsado por las nieblas de los primeros escarceos de Apro y Materno", pero ese es el "asunto y presupuesto" del Dial.

Las anteriores discusiones colocan a M. en la mejor posición para desarrollar el apartado dedicado a la estructura del Dial. (cclxxxi-ccciv). Da cuenta de los más importantes estudios dedicados a esa cuestión y emprende él mismo "una paráfrasis más o menos libre" del texto de la obra. En realidad es mucho más que eso porque en el curso de su tratamiento se resumen y cuestionan las opiniones de los estudiosos y se tratan problemas específicos que a su vez se relacionan con otros ya tratados, como el de la prosopografía, u otros que aguardan un posterior tratamiento especial, como el de la tradición manuscrita de la obra. El tema principal no aparece hasta el capítulo 14, con la llegada de Vipstano Mesala, especialmente en su segundo discurso que está mutilado por una laguna entre el cap. 35 y el 36. Antes, en 28.2, ha nombrado una primera causa para explicar la decadencia de la elocuencia, la desidia iuuentutis et neglegentia parentum et inscitia praecipientium et obliuio moris antiqui. Para justificar su opinión empieza por referirse al programa de los antiguos sistemas educativos y a compararlos con los modernos. Hay aquí, nos parece, una premonición de las muchas veces que se planteará la querelle des anciens et des modernes. En cuanto a la mencionada laguna que quiebra su intervención, se discute su extensión y contenido y se plantea la pregunta de quién es el que está en uso de la palabra cuando vuelve el texto. Sobre esto último hay consenso en que se trata de Materno. Y aquí surge una cuestión peliaguda: el tenor de esta última intervención del personaje y de la obra deriva claramente hacia lo político y, concretamente, hacia una postura claramente antirepublicana. Y eso se compadece mal con la imagen de defensor de la libertad que al principio de la obra ofrecía Materno. Teniendo en cuenta el embrollo prosopográfico sobre Materno ya comentado, no ha de extrañar que algunos propongan resolver "el problema de los dos Maternos" (van den Berg) atribuyendo a dos personas distintas los dos alegatos, pero Strunk, siguiendo a Bartsch, ha dado una sofisticada solución a ese problema sin necesidad de doblar a los Maternos. 
Al final de la paráfrasis M. plantea una última e importante cuestión, la de "si sus parlamentos se atienen a una estructura, a un cierto Aufbau", que permita considerar el Dial. como una obra unitaria. Tras una discusión de las opiniones controvertidas al respecto M. se inclina por una repuesta positiva a la misma.

M. toma de nuevo explícitamente a Gudeman como guía para desarrollar el apartadodedicado a la lengua y estilodel Dial.(cccv-cccxxvi), pero por supuesto enriquece ese "cañamazo" con la discusión de las aportaciones posteriores y de la suya propia. En su elección de los rasgos "de particular interés" de la lengua del Dial. expone primero un acertado criterio metodológico: es interesante cuanto suponga un cierto desvío de la norma -mucho menor, por cierto, que el que se observa en su obra mayor-, pero también cuanto suponga una adhesión a ella. Esa norma, afirma, permitirá "despacharse de manera bastante sumaria" con este importante tema. No debe el lector tomarse demasiado en serio el concepto de "sumario" que tiene el autor ni es propio de él y de su dominio de los problemas y de la bibliografía dejarse nada en el tintero de la filología. Así que ahora siguen veintiuna páginas en las que se abordan, por lo que hace a cuestiones propiamente lingüísticas, el vocabulario, el uso de los casos y de los modos, el tratamiento del periodo condicional, el empleo del subjuntivo, el uso de las perífrasis verbales y, en fin, el tratamiento de la concordancia. Por lo que hace a cuestiones estilísticas se atiende a la collocatio uerborum, la anástrofe del cognomen, la posición de los verbos, la anástrofe del adverbio, el uso de las preposiciones, el recurso a la aliteración silábica, las figurae uerborum, el polisíndeton y el asíndeton, la anáfora, el climax, la oratio bimembris o trimembris. M. cierra esta larga e importante relación tratando un "asunto de estilo por excelencia”, por cierto no tratado por Gudeman, a saber el del uso del numerus de la prosa oratoria en el Dial. Aporta los datos recabados por Mayer, que describe sucintamente, y los enriquece con los datos recabados de sus propias pesquisas (cccxxi, n. 249). Este apartado se cierra con la referencia a los estudios que han intentado establecer características de síntesis del Dial. extraídas de la observación de los usos antes relacionados. Entre esos estudios destacan los de Gudel quien, además, ha analizado separadamente los rasgos de los parlamentos de cada uno de los intervinientes en el diálogo, en un intento de individualizar el estilo de cada uno de ellos.

La tradición manuscrita del Dial. presenta una situación parecida a la de la Germ.: el texto está preservado en diversos manuscritos del s. XV que derivan, en último término, del perdido Hersfeldensis. M., pues, procede (cccxxvi-cccxxx) a indicar los 12 mss. que se citan de forma constante en su aparato (además de algunos otros citados ocasionalmente: cf. cccxxvi, n. 258) y resume muy sucintamente los diversos y, por lo general, un tanto infructuosos intentos de establecer de forma convincente la relación entre los códices y, de nuevo, se muestra escéptico sobre la utilidad de la distinción de familias "a la hora de obtener un mejor texto" (cccxxvii), siguiendo la línea de Önnerfors en la Germ. y de Heubner en el Dial. (cf. cccxxvii, n. 259). 
Aunque M. en este caso también entiende que la valoración de los mss. va estrechamente relacionada con la historia editorial de la obra, la panorámica sobre las ediciones se presenta esta vez en un apartado específico, que incluye también mención de los comentarios y de las traducciones de ámbito hispánico (ccxxxv-cccxxxviii). Por otra parte, M. recuerda (cccxxxviii-cccxxxix), una vez más, que el suyo será un texto revisado y reconoce su deuda especial con Winterbottom (1975), Heubner (1983), Flach (2005) y Mayer (2001), pero también con los diversos trabajos de Murgia.

Colocado "a la sombra -y nunca mejor dicho- de un vasto corpus literario latino concerniente a los mismos asuntos por él tratados”, avisa M. al principio del apartado dedicado al Fortleben del Dial. (cccxxxii-cccxxxv), no se podía esperar que el impacto de un breve opúsculo -uno más, entonces- fuera importante. De hecho, ningún texto antiguo hace mención ni del Dial. ni de ninguna de las obras menores de T. Es posible que en autores tardoantiguos haya alguna no confesada influencia del Dial., señaladamente en Minucio Félix la forma dialogada de cuyo Octauius favorece la existencia de posibles deudas de éste con el Dial. Se han señalado también (Cabrillana siguiendo a Mazzarino) pasajes de Frontón y de los Panegíricos latinos y de Sidonio Apolinar. Todo esto parece apuntar con más dudas que certezas a la recepción del Dial. en la Antigüedad y en la Spätantike. Arrebatada la atención de los humanistas hacia las recién descubiertas obras mayores de T. y discutida la autoría del Dial., la situación no mejora apreciablemente en el Renacimiento, de manera que la presencia de la obra "apenas transcendió del ámbito filológico”.

\section{EL TEXTO Y EL APARATO CRÍTICO}

Aunque M. ofrece, como ya hemos visto, un "texto revisado" y las lecturas de manuscritos han sido tomadas de otras ediciones (con la excepción de E en Agr. y, aunque ahí no tiene un valor especial, en Germ.), conviene hacer algunas observaciones a propósito del texto y del aparato crítico que lo acompaña. Por dos razones: primero porque, a pesar de que M. diga, por exceso de modestia, no tener un criterio sólido para juzgar variantes y conjeturas (e.g. cxci), no duda en diferir de sus predecesores cuando lo estima oportuno, a veces incluso señalando brevemente en nota los motivos que hay detrás de su elección; en segundo lugar, porque el aparato es notoriamente más extenso que, por ejemplo, el de las ediciones, que podemos considerar estándar, de la OCT (Winterbottom-Ogilvie ${ }^{9}$ ) o de la Bibliotheca Teubneriana $\left(\right.$ Delz $^{10}$, Önnerfors ${ }^{11}$, Huebner ${ }^{12}$ ).

${ }^{9}$ Vid. n. 2.

${ }^{10}$ Vid. n. 3 .

${ }^{11}$ Vid. n. 7 .

${ }^{12}$ H. Huebner (ed.), Corneli Taciti libri qui supersunt, Tom. II, Fasc. 4, Dialogus de oratoribus, Stutgardiae 1983. 
En cuanto al texto editado, como es lógico, podemos discrepar con la lectura aceptada aquí o allí por M., pero esto tiene más bien poca importancia, puesto que, por lo general, el texto editado es pulcro y, en los numerosos loci desperati, por lo menos plausible ${ }^{13}$. Señalamos, a modo de ejemplo, tres casos en que el texto difiere del de las ediciones estándar, creemos que de forma acertada:

Agr. 23.1 inuentus in ipsa [sc. aestate] Britanniae terminus.

M. acepta la conjetura de Shaw-Smith, Britanniae en lugar de Britannia, defendida de forma convincente por parte de Woodman $^{14}$. Cf. 30.3 nunc terminus Britanniae patet; 33.3 finem Britanniae ... tenemus. Probablemente se trate de un error por asimilación.

Germ. 13.2 ceteri[s] robustioribus ... aggregantur

El texto transmitido ceteris, admitido por la mayoría de editores, no sin dudas por parte de Winterbottom ${ }^{15}$, nos parece inaceptable. ¿Quiénes son los ceteris robustioribus? M. hace muy bien reivindicando la fácil y excelente conjetura de Lipsius.

Dial. 16.7 Demosthenes uester

La lectura de los códices (SUEV) uester, rechazada por la mayoría de editores, nos parece plausible a la vista, por ejemplo de 18.1 Caluus uester, también puesto en boca de Apro. Era una lectura también defendida, aunque M. no lo menciona, por Murgia ${ }^{16}$ precisamente en virtud del mismo paralelo que acabamos de aducir. En favor de uester podría citarse también 10.3 cothurnum uestrum, que aparece en el primer discurso de Apro. La variante uidetur (BCQ), editada y considerada como interpolada por la mayoría de editores, se puede explicar con relativa facilidad por razones paleográficas: Murgia sugería, plausiblemente, que la lectura del arquetipo era $u \bar{r}$.

En sentido contrario, indicamos algunos lugares en que el texto editado por M. nos plantea dudas:

\footnotetext{
${ }^{13}$ Debemos señalar que, salvo error u omisión por nuestra parte, M. ha evitado incorporar propuestas propias, ni siquiera en el aparato, probablemente por la misma modestia a la que acabamos de aludir.

${ }^{14}$ A. J. Woodman (with C. S. Kraus), Tacitus: Agricola, Cambridge 2014, 212.

${ }^{15}$ Winterbottom, Ogilvie, Opera minora, 44.

${ }^{16}$ C. E. Murgia, "Loci Conclamati in the Minor Works of Tacitus", California Studies in Classical Antiquity 11, 1978, 159-78, 175-6.
} 
Agr. 22.2 castellum aut ui hostium expugnatum aut pactione aut fuga desertum

M. prefiere leer aut fuga con $\mathrm{E}^{2}$, que quizá es "lectio facilior", mientras que la mayoría de editores prefiren ac fuga de $\mathrm{E}$, puesto que la secuencia aut ... expugnatum ... aut ... desertum recomienda evitar aut para coordinar pactione y fuga. Cabría quizá la posibilidad, como sugiere Woodman ${ }^{17}$, de entender pactione ac fuga como una hendíadis con el sentido de 'a negotiated desertion'; es decir, entender que pactio y fuga no son excluyentes entre sí. ¿Pero podríamos pensar en uel o seu?

\section{Germ. 3.2 Vlixen}

Los mss. oscilan entre Vlixen, Vlyxen, Vlixem o Vlissem. Los códices, si son de fechas tardías y, especialmente, en lo que se refiere a los nombres propios, tienen una autoridad muy limitada en materia ortográfica. En latín, según parece, la forma correcta es Vlixem: cf. A. E. Housman, JPh 31, 1910, 259-60.

Dial. 21.1 †ganuti aut atii de furnio et coranio $†$

M. traduce " $<\mathrm{C}>$ anuc $<$ io $>$ o A $<$ rrio, por no decir nada $>$ de Furnio y Toranio", que se corresponde con las conjeturas de Gronovius, Canutium en lugar de ganuti y Arrum en lugar de atti, el suplemento de John dico ne quid loquar (aceptado por no pocos editores), y la lectura toranio de bH. Las conjeturas de Gronovius nos parecen bastante probables, mientras que el suplemento de John es solo una plausible tentativa. Quizá habría sido más adecuado editar el texto conjetural con las debidas prevenciones en aparato o en nota.

Dial. 22.4 sit in apparatu eius et aurum et gemmae, ut sumere in manus et aspicere saepius liceat.

M. prefiere aquí la lectura de los mss. liceat, mientras que casi todos los editores aceptan la impecable conjetura de Agrícola libeat. La justificación aportada en nota por M. (133, n. 152) de que se trata de "una oración final que manifiesta una intención [cursiva de M.] del hablante" no es una prueba clara a favor del texto transmitido, puesto que la subordinada podría entenderse también como consecutiva. En realidad, la traducción de liceat como 'pueda' nos llevaría a esperar en todo caso possit. Además, el sentido de liceat resulta seguramente un tanto débil en este contexto. La conjetura libeat, pues, parece preferible.

${ }^{17}$ Woodman, Agricola, 209. 
En los prólogos al Agr. (lxxxv) y Germ. (cxci), M. se excusa de la densidad y extensión de su aparato. Sin embargo, aportar el mayor número de lecturas de los manuscritos y de conjeturas no es una "servidumbre propia del editor que reconoce no tener la autoridad necesaria", como afirma M. (lxxxv), sino que, en nuestra opinión, es un paso imprescindible para el esclarecimiento crítico de cualquier texto antiguo. De algún modo, nos parece significativo que, al abordar el Dial., probablemente la peor transmitida de las obras menores de T., M. ya no sienta la necesidad de excusarse por la extensión del aparato. En realidad, como trataremos de mostrar más adelante, los aparatos podrían todavía presentar más información. Puede servir como muestra de la amplitud del aparato Agr. 28.1, uno de los pasajes más controvertidos y más diversamente corregidos de la obra. M. edita la conjetura de Woodman uno remig<i imper $>$ ante y en el aparato consigna, aunque de forma algo confusa, soluciones de, entre otros, Puteolanus, Gudeman, Delz, LópezCañete, Huebner o Wellesley. Igualmente, en nota $(29$, n. 112), M. remite al comentario de Ogilvie-Richmond para otras soluciones. Por contra, Delz ${ }^{18}$ cubre rápidamente el expediente con un alii alia y Ogilvie ${ }^{19}$ pasa prácticamente en silencio el problema textual.

La voluntad de exhaustividad también se manifiesta en un intento de dejar constancia de las diversas soluciones adoptadas por los editores a partir del s. XX. Sin embargo, ello no se ha realizado de manera sistemática y a falta de una justificación (no la hemos encontrado en los prólogos), no está muy claro qué criterio ha seguido M. a la hora de mencionar o no las lecturas adoptadas por parte de los editores recientes. A veces, M. cita bastantes ediciones, mientras que en otros casos se citan sólo algunas o ninguna. Veamos un ejemplo de los dos extremos:

Agr. 3.1 et $^{1}$ codd., Gudeman, Koestermann, Till, OgilvieRichmond, Ogilvie, Lund (1981), Städle, Oniga, Woodman. [sic] : set ed. Bipont. (1780) : sed Croll, Halm, Saint-Denis, Delz, Soverini, al.

Agr. 3.2 multi Lips. [sic; en la mayoría de ocasiones el nombre no aparece abreviado]: multis codd.

En el segundo caso, probablemente hay que entender que la mayoría de editores aceptan la excelente conjetura de Lipsius, pero habría sido recomendable explicitarlo, como en otras ocasiones:

Agr. 2.1 legimus codd., edd. plerique : uidimus Lipsius (recte ut opinatur Delz in app. et Mus. Helv. 27, 1970, 236)

${ }^{18}$ Delz, Agricola, 21.

${ }^{19}$ Winterbottom, Ogilvie, Opera minora, 20. 
Es verdad que indicar cuál ha sido la elección de variantes y conjeturas por parte de los editores en los distintos pasajes de un texto, no constituye per se una información relevante para el establecimiento del texto ${ }^{20}$. Pero, al mismo tiempo, es innegable que, en una disciplina histórica como la nuestra, la historia impresa del texto también tiene su relevancia y, desde ese punto de vista, recoger las lecturas de las ediciones precedentes (o por lo menos de las más significativas) es sin duda una información valiosa. Por esa misma razón, es cuestionable que esa información esté limitada a las ediciones del s. XX. Por poner solo un par de ejemplos, quizá habría sido interesante poder apreciar el impacto sobre el texto de la edición de Lipsius (y de algunas otras históricamente importantes) o del descubrimiento del Aesinas para el Agr.

En cualquier caso, nos parece que algunos defectos formales convierten los aparatos críticos en el aspecto más irregular del volumen, quizá por falta de una última y exhaustiva revisión de los mismos. Lamentablemente, son demasiadas las entradas de los aparatos que, más que ponerlo en claro, no permiten observar de forma clara y sin ambigüedades el status quaestionis del texto y las fuentes del texto editado. Aquí, como es comprensible, nos limitaremos a ofrecer una muestra de los problemas que hemos identificado. Esperemos que una revisión a fondo, en vistas a una deseable segunda edición, pueda enmendar esas carencias.

El orden de las entradas del aparato, en ocasiones, no refleja el texto editado y traducido. En otras palabras, no siempre se reserva en el aparato el primer lugar para el texto editado, lo que puede inducir a confusión. Indicamos algunos ejemplos (reproducimos primero el texto editado y luego la entrada del aparato) ${ }^{21}$ :

Agr. 12.3 parte Britanniae

Britanniae parte $\mathbf{e A}$ : parte Britanniae $\mathbf{B}$

Germ. 5.1 arborum patiens

impatiens codd., [falta la coma] Gudeman, Anderson, Lenchantin : patiens Tross, Murgia $\left(1979^{a}, 166\right)$

${ }^{20}$ Cf. J. R. Tarrant, Texts, Editors, and Readers. Methods and Problems in Latin Textual Criticism, Cambridge 2016, 135-6.

${ }^{21}$ Hemos advertido otros ejemplos en Agr. 13.1 potitus sit; 30.1 co<is $>$ tis et $<$ iam $>; 43.3$ animo; 46.2 decoremus; 46.4 obruit; Germ. 12.2 principes; 20.1 ac; 20.4 tanto; 37.2 Metello et Papirio; 39.1 omnes eiusdem[que]; 40.1 plurimis ac; 43.2 Helysios; 44.1 Gotones; 46.1 sordes omnium; Dial. 10.8 [expressis]; 13.4 quibus <parcius >; 14.1 Messalla; 14.2 minime, minime; 17.3 qua; 22.4 supellectili; 29.4 nec ... quidem [en este caso la conjetura de Gronovius ne es claramente correcta]; 31.2 nec ... neque; $32.3<$ hu>ius; 36.2 persuaderi; 39.2 omnia alia depacauerat. 
Dial. 3.3 tu quid Maternus

quod C : quid cett., edd. : <inquit> quid Halm, Goelzer [además, en este caso existe riesgo de confusión con el quod que inicia la siguiente frase]

Un caso especialmente significativo es:

Dial. 41.5 si aut uos prioribus saeculis aut illi quos miramur his nati essent ac deus aliquis uitas ac [uestra] tempora repente mutasset, non uobis summa illa laus et gloria ... neque illis modus et temperamentum ... defuisset.

et Wagener, Gudeman, Koestermann, Winterbottom, Flach : aut codd., Huebner $\bullet$ illi Halm : istis $\mathrm{C}$ : isti cett. codd. $\bullet \mathrm{ac}^{2}$ : et E : om. V [esta entrada debería aparecer después de la siguiente] - aut deus ,[sic, falta “ $\Delta$ " = Vat. lat. 4498] Wagener, Flach : ac deus cett. codd., Winterbottom, Heubner -[uestra] del. Halm : uitas uestras ac tempora Bekker

La prótasis condicional presenta distintos problemas. Materno, creemos, ofrece dos hipótesis distintas: 1) que sus interlocutores hubieran nacido en una época anterior y los antiguos oradores, a su vez, hubieran nacido como contemporáneos de los participantes en el Dial.; 2) o que un dios alterara las 'épocas'. Por lo tanto, la secuencia transmitida y editada por M. aut ... aut ... ac no parece óptima. El aparato sugiere que M. quería aceptar, o por lo menos consideró, las propuestas de Wagener ${ }^{22}$ aut ... et ... aut, que ofrecen el sentido requerido con unos cambios menores (si quisiéramos acercarnos un poco más a lo transmitido quizá podríamos sugerir aut ... ac ... aut $)^{23}$.

Por otra parte, la supresión de uestra por parte de Halm, aceptada por la mayoría de editores, soluciona el principal problema de la segunda alternativa propuesta por Materno: el dios debería alterar tanto la época de los oradores antiguos como la de Apro, Secundo y Mesala. De todos modos, la expresión uitas ... mutasset ha suscitado ciertas dudas, puesto que, según parece, el

${ }^{22}$ La primera entrada del aparato es poco clara, puesto que el lector no puede entender de inmediato que el aut afectado por la conjetura de Wagener es el que hay en los mss. después de saeculis. Hay por cierto, una errata en la referencia bibliográfica al trabajo de Wagener (ccclxii). La cita correcta es A. Wagener, "Les travaux de Monsieur G. Andresen sur le dialogus [no dialogue] de oratoribus", Revue de l'instruction publique en Belgique [no Bergique] 20 [no 10], 1877, 257-84. El pasaje en cuestión se trata en 283-4.

${ }^{23}$ Debemos asimismo indicar, en contra de lo que dice M., que tanto Koesterman (P. Cornelii Taciti libri qui supersunt, edidit E. Koestermann, tom. II, fasc. 2, Germania, Agricola, Dialogus de oratoribus, Lipsiae 1949, 109) como Winterbottom (Opera minora, 106) editaron el texto transmitido aut ... aut ... ac. 
dios debería cambiar los tempora, pero no necesariamente las uitas. Wagener sugería uetera ac uestra tempora, que, aunque tampoco nos parece una solución satisfactoria, consideramos mucho más interesante que la propuesta de Bekkker. Por su parte, Andresen ${ }^{24}$ consideró ac deus ... mutasset como una interpolación, lo que constituye una solución drástica que renuncia a intentar enmendar el texto. Quizá uitas ... mutasset se puede defender confrontándola con Cic. Sull. 69 neque cuiusquam repente uita mutari [sc. potest] aut natura conuerti.

Otro error recurrente de los aparatos críticos, especialmente en Agr., es que $M$. no es coherente al seleccionar el tramo de texto en que se encuentra el término o los términos objeto de crítica, lo que resulta desconcertante y obliga al lector a elucubrar para comprender qué texto ofrece cada testimonio manuscrito o cuál es la propuesta de los distintos eruditos. Ello provoca, además, que en ocasiones el lector extienda sus dudas hacia otras entradas que, en principio, son impolutas. Véamoslo con un ejemplo, en el que, además, el orden de las entradas tampoco parece óptimo.

Agr. 10.3 unde et in uniuersum fama est; sed transgressis inmensum et enorme spatium ...

unde et in uniuersum fama est trangressis unde et uniuersis fama sed e [...] : fama est transgressa sed Rhenanus : fama; sed transgressis Peerlkamp (post Doederlein, Feilitzsch), Woodman : fama; (:) sed transgressis Peerlkamp, OgilvieRichmond, Ogilvie, Soverini : fama. sed transgressis et Gudeman post Purser : fama est trangressis AB : fama est. trangressis Delz, Oniga : est secl. Schömannn [ [sic], Anderson, Koestermann, alii : unde et uniuersis fama add. $\mathrm{A}^{\mathrm{m}}$ : unde... fama. sed <...> trangressis Städele, alii alia

A nuestro modo de ver, el aparato no permite que el lector comprenda de forma clara cuál es la fuente del texto editado. Parece que se trata del texto de Peerlkamp, citado por duplicado en el aparato, con el añadido de est como parece estar en los mss. y en Delz ${ }^{25}$. Además, los mss. AB, en lugar de fama est sed trangressis editado, leen fama est trangressis $\operatorname{sed}^{26}$, lo que explica mejor la conjetura de Rhenanus.

${ }^{24}$ G. Andresen, "Emendationes Taciti qui fertur dialogi de oratoribus”, en F. Ritschel (ed.), Acta societatis philologae Lipsiensis I, 1871, 103-82, 176-7.

${ }_{25}$ Delz, Agricola, 7.

${ }^{26}$ No hemos podido verificar la lectura de A (Roma, Biblioteca Vaticana, Vat. lat. 3429), pero así consta en el aparato de Ogilvie (Opera minora, 9); sí, en cambio, hemos verificado la lectura de B (Roma, Biblioteca Vaticana, Vat. lat. 4498). 
Dificultades similares, se encuentran en los aparatos de Agr. 9.3 tristitiam et arrogantiam et auaritiam exuerat; 12.5 [pecudumque] fecundum; 13.3 auctor iterati operis; 16.4 pacta ac exercitus licentia $<e t>$ ducis salute; 20.3 ut <haec ut>; 22.2 aut fuga; 24.1 differunt; in melius; 28.1 et uno remig<i imper>ante, suspectis duobus eoque interfectis; 31.4 in paenitentiam parati; 34.2 ignauorum et timentium; 36.3 equitum turmae; $36.3<u t>$ fugere couinnarii; 36.3 equestris ea pugnae facies; 42.2 paratus simulationi; 42.4 plerique per abrupta; 43.2 adfirmare; 44.4 opibus ... contigerant; 44.4 filia ... superstitibus; 45.1 nos Maurici Rusticique uisus; Germ. 30.2 Romanae disciplinae; 37.5 pulsi. nam; 38.2 apud Suebos ... sequuntur; 38.2 comptius ... ornantur; 45.2 illuc usque, ut fama fert, tantum natura; 46.1 ac torpor procerum; Dial. 5.4 inuenero; $7.3<$ sunt $>$ in urbe; 8.1 non minus $<$ notos $>$; 15.1 oratorem esse contenderes $<$ parem>antiquis; 19.1 †qui usque ad Cassium †, quem; 21.1 †ganuti aut atii de furnio et coraniof; 26.8 ante Ciceronem ... post Gabinianum; 27.1 parce; 29.1 [et uirides] teneri statim et rudes; $32.3<h u>i u s ; 32.6$ non rhetorum <officinis>; 40.1 populi ... uterentur; 40.4 sicut indomitus. Nos parece asimismo que las entradas correspondientes a Dial. 16.6 uideatur y 16.7 uester se han mezclado.

Otra dificultad de lectura del aparato, probablemente más responsabilidad de la editorial que del autor, es que algunas entradas del aparato no aparecen en la página que les corresponde. Lo hemos apreciado en las pp. 16, 43, 53, 55, $58,65,70,115$ y 116 .

Para concluir este apartado, en consonancia con lo que decíamos a propósito de la cita de las lecturas adoptadas por los distintos editores, hay que lamentar que, como algunos de sus predecesores, M. no haya tenido también en cuenta, de primera mano, algunas ediciones y conjeturas antiguas. Ello es especialmente necesario en el caso del Dial., puesto que se trata de un texto bastante mal transmitido y en el que todo progreso, según parece, debe pasar por la enmienda conjetural. En realidad, esto no es una crítica tanto a M. y a la edición que reseñamos como a los editores de las obras menores de T. en general. Algunas conjeturas que pueden parecer arbitrarias, pueden servir para alertar al lector de posibles problemas del texto y pueden ayudarlo a interpretarlo con mayor atención. Ahí van, pues, unas pocas notas, sin ningún ánimo de exhaustividad, para los primeros diez capítulos del Dial. Los datos proceden de la edición de Ernesti ${ }^{27}$.

${ }^{27}$ C. Corneli Taciti opera ex recensione Io. Augusti Ernesti, Tomus secundus, Lipsiae 1772. El Dial. está editado en 525-76. Las notas de Heinsius al Dial. están en 751-2. 
Dial. 3.3 maturare libri huius editionem festino

Gronovius sugirió gestio, que es muy atractivo y digno de mencionarse, aunque puede que sea un cambio innecesario. Heinsius todavía conjeturó destino "minima mutatione" y aportó el paralelo de Ov. met. 8.151.

Dial. 6.3 homines ueteres et senes

M. menciona la brillante, aunque no incuestionable, conjetura de Heinsius diuites en lugar de ueteres para evitar la tautología ueteres/senes. En sus notas, todavía sugería locupletes o locupletiores e incluso caelibes comparándolo con 6.2 orbos et locupletes et potentis. Pero admitía "nondum mihi satisfacio".

\section{Dial. 6.3 totius orbis gratia}

Pithoeus conjeturó hábilmente urbis, a lo que Lipsius apostilló "probe". La conjetura fue aceptada por Pichena. Vrbis parece tener algo más de sentido en el contexto inmediato (6.4 togatorum comitatus et egressus, etc.).

Dial. 7.3 tum habere quod, si non in alto oritur, nec...

Se trata de un "locus conclamatus". En el aparato de M. falta la atribución de la conjetura habere a Pithoeus. Además, habría sido interesante mencionar algunos intentos de mantener el transmitido abire mediante un suplemento: tum supra me abire (Lipsius), tum in caelum abire (Dousa, Heinsius). Se trata de una opción a considerar, dado que la parádosis del Dial. contiene frecuentes lagunas de unas pocas palabras, que deben completarse con suplementos más o menos tentativos (cf., e.g., $5.4<$ uel ad uoluptaem dulcius $>$ [cf. 6.1-2], $6.6<$ in>; $7.3<$ sunt $>$; $8.1<$ notos $>$; passim). Debería mencionarse también la conjetura in ipso en lugar de in alto de Ernesti, que anticipa la de Nipperdey.

Dial. 7.3 adolescentes, quibus modo recta indoles est

Parece que el primero a editar el texto así fue Broterius, que lo tomó "e MSS. Vatic.”.

Dial. 8.3 Vespasianus, uenerabilis senex et patientissimus ueri

La nota de M. (111 n. 44) a propósito de patientissimus ueri remite, siguiendo a Cabrillana, a Suet. Vesp. 13, que no justifica realmente el texto transmitido. Mucho más adecuado es Sen. Dial. 5.36 .4 (citado por Mayer). Antes de Lipsius, según parece, la mayoría de ediciones leían uir en lugar de ueri. Otros editores se han preguntado igualmente cuál es el sentido de la 
expresión y han tratado de corregirla. M. podría haber citado algunos otros intentos: sapientissimus uir (Acidalius), paci intentissimus uir o publicae attentissimus rei (Heinsius, quien proponía todavía otras opciones, aunque ninguna parece muy adecuada a lo que sigue).

Dial. 10.5 minus obnoxium sit offendere poetarum quam oratorium studium

Parece que se trata del único caso documentado de obnoxius con infinitivo (cf. $O L D$ s. v. 5; ThLL 9.2.128.69-71). La construcción normal de obnoxius es con dativo. Acidalius conjeturó un brillante offensae (cf. 3.2 offensas Catonis; 10.6 nec excusatur offensa), que M. no menciona (sí la cita Koestermann ${ }^{28}$ ). Los copistas habrían podido corromper fácilmente offensae en offendere al no entender bien la construcción. Por otra parte, la lectura oratorium editada por M. parece un error deslizado quizá desde 10.3 oratorium ingenium; el paralelismo con poetarum exige oratorum.

LA TRADUCCIÓN Y LAS NOTAS

Al principio de estas páginas recordábamos que hace ya muchos años $\mathrm{M}$. publicó la mejor traducción española que existe de los Anales de T. Pues bien, esta que ahora nos ofrece de sus obras menores, la que acompaña a su texto, no desmerece de aquella. Puede que atrape menos al lector, puede que este no encuentre aquel dramatismo, aquella expresión concentrada y abrupta, aquella despiadada ironía, en fin todo eso que hace de T., al decir de Racine, "le plus grand peintre de l'Antiquité". Pero la culpa es de T., no del traductor. Dicho de mejor manera, el inconfundible estilo de T., como M. nos ha recordado, está contenido en las obras menores casi solo in nuce. Solo al principio de las Historias comienza aquella parábola de dificultad creciente, ya descrita por Wölflin y Löfstedt, que progresa en ellas, alcanza su ápice en la primera parte de los Anales y se convierte en decreciente en la segunda hasta ofrecer un estilo menos alejado de la prosa clásica. M. habrá tenido que hacer abstracción del estilo que hizo suyo como traductor de los Anales para acometer ingenuus esta nueva tarea.

Veamos algunos ejemplos de esta traducción, siempre fiel pero que nunca retuerce el castellano, nunca suena a "español de traducción”. Los tomamos preferentemente del Agr. Con frecuencia M. nos parece certero en la traducción que elige para una palabra latina polisémica: "personalidad" para mores (Agr. 1.1), "sumisión" para patientia (Agr. 2.3) "cálculo" para ratio (Agr. 6.4), "lánguido y deslomado" para fractum et elumbem (Dial. 18.5); luxuria se vierte por un castizo "desmadre" cuando se resume un texto de Séneca Rétor (cclxxvii), pero es "despilfarro" para referirse al exceso en que

${ }^{28}$ Koestermann, Germania, Agricola, Dialogus, 76. 
nunca cae Agrícola (Agr. 6.5) y "afán de lujo" lo que lleva a los romanos a codiciar el ámbar (Germ. 45.4): son variaciones de virtuoso propias del excelente latinista y traductor que es M. No vacila en amplificar cuando de esta manera vierte mejor el concepto latino, así en "presente generación" por aetas (Agr. 1.1), "el propio atractivo de no hacer nada" por inertiae dulcedo (Agr. 3.1), "valiéndose de maquinaciones" por artem (Agr. 9.4), "buena persona" por innocens (Agr. 16.5), "metía en cintura a los que andaban a su aire" por disiectos coercere (Agr. 20.2). En alguna de estas elecciones, como en esta última M. recurre con acierto a un tono coloquial, así también en la ya mencionada traducción de "desmadre" por luxuria y en el ingenioso empleo de la locución "vaya que sí" por el gramaticalizado hercule (passim). Suele respetar los periodos largos, no demasiado frecuentes en estas obras que todavía no son, valga la expresión, plenamente "tacíteas", pero no vacila en desglosarlos cuando el resultado en castellano sería demasiado fatigoso. Parece oportuno señalar aquí un pasaje (Agr. 3.2) ciertamente famoso porque es el que contiene la tantas veces citada expresión grande mortalis aeui spatium, en el que traducción y anotación nos producen cierta confusión. En la traducción M. opta por cerrar con puntuación una primera oración, la acabada en interciderunt y empezar una nueva oración principal en pauci, lo que nos parece muy acertado; en el texto latino ha mantenido el largo periodo y no ha cerrado la interrogación hasta uenimus. Nada que objetar a este proceder, pero despista un poco lo que dice en nota (p. 5, n. 16), donde se refiere a los que así puntúan con la expresión "algunos propugnan" lo que podría dar a entender que no es su elección; y sí que lo es, a pesar de que no sea ese el texto editado. En otros casos disentimos, con vacilación, de la traducción de M., por ejemplo, en Agr. 9.2 quia castrensis iurisdictio secura etc. M. traduce "irresponsable" por secura, pero pensamos que "irresponsable" tiene un sentido negativo en español que no está en el latín que se limita a señalar que la jurisdicción militar "no tiene que dar cuentas", está, como por ejemplo traduce Saint-Denis, "exempte de contrôle". Por último, no podemos dejar de destacar la traducción de Dialogus de oratoribus como "Diálogo sobre los oradores", que, como dice M. (ccxxv, n. 1), resulta "más estrictamente fiel al sentido" y menos ambigua respecto a la habitual "Diálogo de los oradores".

La densidad y erudición, siempre bien administrada, de los estudios introductorios se vuelve a dar en las notas, que constituyen un verdadero comentario de estas obras menores de Tácito, donde no hay problema textual, geográfico, histórico, lingüístico, literario- que no haya sido tratado con la profundidad que permite el espacio destinado a ello, a veces muy generoso, lo que es de agradecer. Es ahí donde M. nos sorprende a menudo, como ya hemos mencionado antes, con "excursiones" propias de su extensa cultura que nos llevan aparentemente muy lejos del tema, pero que lo ilustran de manera inusitada. Ya lo hemos visto, en su estudio sobre la recepción de la Germ., pero hay muchos más ejemplos; así, uno de los aspectos de la 
formación militar que importa a Agrícola, nihil appetere in iactationem, nihil ob formidinem recusare (Agr. 5.1) le lleva a recordar un pasaje nada menos que de Calderón ( 7, n. 26); una observación de T. sobre que, para designar entre los germanos a un cuerpo escogido de cien guerreros por pago, quod primo numerus fuit, iam nomen et honor est (Germ. 6.3) le recuerda una institución municipal española, la de los "caballeros veinticuatro[s] de los antiguos municipios españoles" (59-60, n. 48); la costumbre entre los germanos de retrasar la iniciación sexual le lleva nada menos que a recordar un pasaje de las Instrucciones de Palamós, las que Carlos V dio a su hijo Felipe II antes de ausentarse de España (71-2, n. 92), texto por cierto cuya enorme importancia solía comentar Antonio Fontán, maestro querido de M.; los delatores Marcelo Eprio y Crispo Vibio (Germ. 8.1) le parecen a Michel, registra escrupulosamente M., "haber sido el Fouché y el Talleyrand ... de aquella época”, y eso le lleva a recordar la famosa expresión de Chateaubriand, "le vice appuyé sur le bras du crime" (Mémories d’outre-tombe, 23, 20) que, efectivamente, bien se podría predicar de estos depravados delatores; y no falta Mozart como término de comparación en el lenguaje musical de las repeticiones de expresiones en las obras de T. (Borzsák, p. 21, n. 91). Algunas veces estas excursiones proporcionan referencias casi humorísticas: una descripción del peinado distintivo de los suevos (Germ. 38.2) merece de M. el comentario de que "tal peinado lo llevan también actualmente algunos jóvenes alemanes"; los teatros romanos en la Edad de Plata los describe justamente M. como degradados "por espectáculos plebeyos y de ínfimo gálibo artístico (al modo de tantos de la moderna TV)", arriesgada opinión que compartimos plenamente (cclxix); M. no duda en calificar como "el fútbol de entonces" (cclxxxviii) la "afición a los histriones y la pasión por gladiadores y caballos" (Dial. 29.3), otro arriesgada opinión que también compartimos. Si hemos reseñado con algún detalle aquellas eruditas referencias y estas sacadas de la vida cotidiana es para agradecer al autor que las haya colocado como puntos para solaz entre la seria prosa filológica que es propia del libro.

En un volumen tan importante, de tan complicada disposición de páginas y tal profusión de notas es imposible que no se hayan deslizado algunas erratas. Señalamos, en primer, algunas significativas en el texto latino: Agr. 14.4 hay que leer circumuecta en lugar de uircumuecta; 15.1 fidissimus en lugar de fidissum; 26.2 paludes et siluae, no paludes el siluae; 30.1 consensumque en lugar de consensusque; 35.3 falta ita después de constiterat; 38.1 debe leerse statim relinquere, no deserere, que se ha deslizado desde la línea anterior (deserere domos); 39.2 occuparet en lugar de occupasset; 45.4 deficientem en lugar de deficientiam; 46.4 posteritati en lugar de posteritatis; Germ. 11.1 maioribus, no maioribis; 14.2 nisi repetido; 17.2 debe leerse nudae bracchia, no nuda; 30.1 sobra una $s$ en 
occassiones; 34.2 falta ubique antes de magnificum; 44.2 falta ut res poscit después de mutabile; Dial. 1.2 falta coma después de possumus; 3.4 falta coma después de nomina; 5.4 fructuosius en lugar de fructiosior; 10.5 oratorum en lugar de oratorium [ya señalado]; 18.5 missas está repetido; 25.7 habría que leer antiqu $<i>$ orum $<$ Aper $>$ agitare, según parece, en lugar de antiqu $<i>$ orum agitare $<$ Aper $>^{29} ; 26.1$ hay que leer aut en lugar de $a u$; 30.5 audientium en lugar de aurium; 33.5 falta ut delante de scientiae; 37.1 debe leerse tamquam en lugar de umquam; 38.1 falta erant después de comperendinationes; 39.2 sobran los paréntesis angulares en quando. Señalamos asimismo que quominus aparece junto en Germ. 28.1, Dial. 21.9 y 34.3 y separado en Agr. 20.2, 27.2, Dial. 3.2 y 3.4. En el aparato, aparte de lo ya señalado: Arg. 17.1 no se identifica la fuente de la lectura [et] terrorem; Germ. 26.2 debe suprimirse "in :" de "in : uices"; en Dial. 38.1 debe corregirse "eloquentiam codd." por "eloquentia codd.".

A parte de estas erratas que se refieren al texto latino, algunas más es oportuno señalar. Un mínimo error tipográfico no llega a perturbar la sobria emoción de la piadosa dedicatoria del libro (vii). Por otra parte, en p. xxxv n. 41, en lugar de "22, 2" debe de decir "21, 2"; p. 2, n. 4, en lugar de fueisset debe decir fuisset; p. cxxiv, en el texto de la página (línea 15) se remite correctamente a los caps. 2-3 de la Germ., pero la nota a pie de página (29) es errónea; p. cxxxii, al final, debe de decir Treuerorum; p. cxlii, al final, debe de decir "cuestiones"; p. cxlviii, n. 87, debe de decir "la" en lugar de "ua"; p. clxxxv, 1. 20 en lugar de "hacia poder" debe de decir "hacia el poder"; la página que debiera ser clxxxviii aparece como clxxxiii; p. cclviii, n. 82, en lugar de 78 debe de decir 80; p. cclxii, n. 89, en lugar de cdxxxv debe de decir ccxxv; p. cclxix, n. 109, debe eliminarse el paréntesis después de "virgilianas"; la n. 51 de la p. 60 es confusa: M. se refiere a los "principes de que habla el original”, pero el original (Germ. 7.1) habla de duces, aunque más adelante (13.1 principum aliquis) habla de principes para referirse a los mismos notables; p. 77 n. 108, "los celtas de allende del Rin" necesitan un verbo; p. $94,1.11$, en lugar de "sus remada" debe de decir "su remada"; en p. 103, n. 8, 1.5 hay un mínimo error creemos que de naturaleza tipográfica, dice IUU en lugar de Ivv, no lo mencionaríamos si no fuera porque parece tener una explicación análoga a la del también mínimo error tipográfico de la p. vii, y son errores interesantes porque pueden ser resultado de un metakharakterismos moderno, en el primer caso al verter una posible versalita original en cursiva, en el segundo al verter una posible redonda del original en versalita. También puede ocurrir que la explicación sea más sencilla y casual. En p. 119, 1. 8, debe de decir "ejemplos"; p. 150, n. 201, reenvía a unas inexistentes pp. cdlxxxvi ss.

\footnotetext{
${ }^{29}$ En el aparato se indica que Winterbottom apostilló la addición $<$ Aper $>$ por parte de P. Voss con "fortasse recte", pero, en realidad, Winterbottom (Opera minora, 89) hizo tal observación a propósito de la conjetura antiqu<i>orum, también de Voss.
} 
Los estudios preliminares a cada obra van seguidos de una extensa -e importante- bibliografía, citada y conocida. Con escrupuloso rigor $\mathrm{M}$. advierte de las veces, muy pocas, en que no ha podido consultar directamente la obra citada. El sistema adoptado para exponer la bibliografía es el de una tabulación en principio muy cómoda: 1. Repertorios bibliográficos, 2. Ediciones, 3. Traducciones, 4. Comentarios, 5. Estudios sobre Tácito y la obra de que se trate y Otras obras citadas. Las repeticiones son inevitables y necesarias: si una edición crítica lleva además comentario, se citará en el apartado 2 y en el 4, etc. Ahora bien, ese sistema se compadece mal con la práctica de citar en el cuerpo del estudio por apellido del autor y año de la obra. El lector se ve obligado a mirar en los cinco apartados y la obra las más de las veces está en uno solo. Probablemente el sistema de la cita de esa manera abreviada aconseja que la bibliografía vaya por orden alfabético en una sola lista. Quizá ese desajuste explica algunos errores o despistes. Así Ballester 2012, debe de ser 2012 ${ }^{\text {; }}$ Moralejo 1983 (por ejemplo, en p. cclxxix, n. 139 y otras veces) no hemos sabido encontrarlo en las listas bibliográficas, suponemos que se trata de la ponencia "La literatura latina en la transición de la República al Imperio", Unidad y pluralidad en el mundo antiguo. Actas del VI Congreso Español de Estudios Clásicos, Madrid, 1983, I, 147202; Norden 1923 (p. 57, n. 33) no está en la bibliografía correspondiente, la de la Germ. (¿es quizá Norden 19594 [1920]?); en p. 127 n. 133, suponemos que Norden $1915^{6}$ es una errata por 1915; Koestermann 1939 no aparece en la bibliografía correspondiente, la del Dial. (y esta vez no sabemos conjeturar la cita correcta).

El volumen, que se presenta con la elegante forma que caracteriza los clásicos de la colección "Alma Mater", viene a ser como tres libros en uno. En efecto, cada una de las obras menores de T. ha merecido por parte del editor, traductor y comentador una crítica minuciosa de todos los aspectos que caracterizan individualmente a cada una de las obras, pero, por otra parte, M. no ha regateado las referencias cruzadas cuando se trataba de problemas comunes - por ejemplo: los que plantea el ms. Aesinas. Intentando un balance de cómo M. se ha enfrentado a tantos y tan diversos problemas podríamos decir que la traducción es sencillamente modélica, los estudios introductorios y la anotación excelentes. Al respecto, no hay que hacer mucho caso de las protestas de modestia del autor que, desde luego, hace mucho más que resumir o dar cuenta del status quaestionis. Por lo que hace al establecimiento del texto, debemos agradecer el intento de exhaustividad y el logro de ofrecer un aparato crítico más amplio respecto a las ediciones estándar -tarea no banal tratándose de obras relativamente mal transmitidas y que presentan numerosos loci conclamati. Por otra parte, parece faltarle al aparato crítico una última revisión que hubiera corregido ciertas incongruencias que ya 
hemos señalado y que desmerecen el buen criterio de $M$. en la selección de variantes y conjeturas.

No sería de justicia acabar sin agradecer al Prof. Moralejo esta nueva y brillante incursión en la obra de Tácito, a la que ya había dedicado contribuciones tan altas como, entre otras, su traducción de los Anales y de las Historias. Ese agradecimiento debe hacerse extensivo a la editorial que ha hecho posible un volumen tan copioso y de tan difícil ejecución.

Pere Fàbregas Salis Universitat de Barcelona pfabregasuni@gmail.com

José LUIS VIDAL Universitat de Barcelona jlvidal@ub.edu 
